\title{
0 dispositivo em Michel Foucault: uma revisão de literatura a partir dos estudos de gênero e sexualidade
}

\author{
The dispositif in Michel Foucault: a literature review \\ based on gender and sexuality studies
}

\section{Maycon Douglas Silva Ribeiro' e Gilson Gomes Coelho'}

\begin{abstract}
Resumo: Os dispositivos se apresentam como caráter de domínio dos corpos, da conduta e da vida humana. Neles estão presentes: discursos, práticas e saberes. $\mathrm{O}$ gênero e a sexualidade são construídos e empreendidos por vários símbolos sociais e culturais. A psicologia como possível dispositivo deve cuidar para não assegurar a vida, bem como quaisquer práticas do sujeito. Este artigo pretende apresentar, discutir e relacionar o conceito de dispositivo do filósofo francês Michel Foucault às categorias de gênero e sexualidade. E por último, refletir sobre como a psicologia no Brasil responde às questões de gênero e sexualidade. Foram analisados artigos científicos na base de dados online: Google Acadêmico, onde limitou-se a busca por temas pertinentes a este trabalho como por exemplo: "dispositivo em Michel Foucault","gênero e sexualidade"," psicologia e dispositivo", etc. A análise culminou em uma revisão integrativa da literatura que permite colaborações de dados diversos de estudos científicos, teóricos e empíricos agregando várias intenções (Mendes, Silveira \& Galvão, 2008). Apenas 15 artigos científicos foram contemplados especialmente por apresentarem os critérios respectivos. Os achados encontram-se disponíveis em tabela neste artigo. Há enorme esforços em torno deste tema, sobretudo em análise pelo conceito de dispositivo em Michel Foucault.
\end{abstract}

Palavras-chave: Gênero; Sexualidade; Dispositivo.
Abstract: The dispositifs have the character of dominance of bodies, conduct and human life. In them are present: speeches, practices and knowledge. Gender and sexuality are constructed and undertaken by various social and cultural symbols. Psychology as a possible dispositif must take care not to guarantee life, as well as any practices of the subject. This article aims to present, discuss and relate the concept of device by the French philosopher Michel Foucault to the categories of gender and sexuality. Finally, reflect on how psychology in Brazil answers gender and sexuality issues. Scientific articles were analyzed in the online database: Google Scholar, where the search for topics relevant to this work was limited, for example: "dispositif in Michel Foucault", "gender and sexuality", "psychology and dispositif", etc. The analysis culminated in an integrative review of the literature that allows collaborations of diverse data from scientific, theoretical and empirical studies aggregating several intentions (Mendes, Silveira \& Galvão, 2008). Only 15 scientific articles were considered especially for presenting the respective criteria. The findings are available in a table in this article. There are enormous efforts around this theme, especially in analyzing the concept of dispositif in Michel Foucault.

$$
\text { Keywords: Gender; Sexuality; Dispositif. }
$$

\footnotetext{
Graduando em Psicologia e participante do Programa Institucional de Iniciação Científica - PROCIENT da Faculdade Católica Dom Orione. E-mail: douglasribeiro018@gmail.com .

2 Doutorando em Psicologia pela Universidade Estadual Paulista " Júlio de Mesquita Filho" (UNESP/ Assis) em que é membro do grupo de pesquisa PsiCUqueer - Coletivos, Psicologias e Culturas Queer. Mestre em Psicologia pela Universidade Estadual de Maringá (UEM). Psicólogo pela Universidade Federal de Mato Grosso do Sul (UFMS/ CPAN). Professor da Faculdade Católica Dom Orione (FACDO). E-mail: gilsonpsico@gmail.com .
} 


\section{Introdução}

De acordo com o autor e filósofo francês Michel Foucault (2006), um dispositivo é qualquer prática discursiva e práticas de fazeres no qual estão representadas pelas nossas condutas. Ou seja, aquilo que fazemos e também aquilo que falamos. Para Foucault (2006), na concepção do dispositivo estão todos os aspectos que envolvem a nossa vida desde um processo histórico, cultural, social e material. Sendo assim, o dispositivo igualmente atua (nestes aspectos que envolvem nossa vida) na aceitação e constituição dos sujeitos, das nossas práticas e de como devemos nos organizar socialmente.

0 dispositivo detém o poder e o saber sobre os nossos corpos; poder que exerce sobre nós em leis para o nosso funcionamento em/na sociedade. Compreende-se que o poder não está em ninguém ou mesmo se encontra em uma instituição; o poder não éalgo que se tome ou que seja arrancado de algum lugar, o poder é uma correlação de forças sobre forças, de açōes sobre ações, o poder não é apenas o Estado, Impérios ou Supremacias, portanto, 0 poder se manifesta de inúmeras formas e se encontra por toda parte (Foucault, 2015). "E esse processo se dá na relação com o outro ou com os outros, razão pela qual o poder é exercido, é ação, ele só existe em ato" (Santos, Lemos, Cardoso \& Brito Neto, 2018, p. 57). Já quanto a0 "saber" para desempenhá-lo bastaria apenas aprender e ensinar (Ferreirinha \& Raitz, 2010).

Como instrumento de nossa análise e revisão é importante não perder de vista as próprias palavras do filósofo Michel Foucault sobre o conceito de dispositivo. É na obra, a História da sexualidade I, a vontade de saber que Foucault fala pela primeira vez sobre 0 dispositivo. Logo, para não perder 0 sentido intrínseco do conceito de dispositivo de Foucault, se faz importante defini-lo a partir de uma outra obra, a Microfísica do poder. É então, que Foucault, define o dispositivo como:

[...] em primeiro lugar, um conjunto decididamente heterogêneo que engloba discursos, instituições, organizações arquitetônicas, decisões regulamentares, leis, medidas administrativas, enunciados científicos, proposições filosóficas, morais, filantrópicas. Em suma, o dito e o não dito são os elementos do dispositivo (Foucault, 2006, p. 244).

Os dispositivos se estabelecem na ligação de cada um desses elementos e se reforçam entre si, justificam discursos e práticas a fim de dominar e subjugar o corpo, a prática ou qualquer expressão da espécie humana (Foucault, 2006). Nesta dinâmica, o dispositivo mantém sob controle a vida das pessoas, das populaç̧ões, da subjetivação dos corpos no decorrer da vida, e estabelece disciplinas aos prazeres (dos corpos), e se ocupa em proteger a espécie humana nas suas diversas configurações da existência: família, educação, relações trabalhistas, etc. (Weinmann, 2006). Cabe ainda dizer, que a heterogeneidade do dispositivo expressa uma dimensão de complexidade; pode envolver desde discursos institucionais, práticas organizacionais, leis, medidas administrativas ou legislativas que estabelecem uma normatização dos comportamentos vivos (Foucault, 2006).

Em última análise do conceito, conforme Foucault (2006) para o dispositivo se tornar real; elementos racionais e organizacionais deverão compor as formaç̃oes da vida humana. Numa perspectiva reelaborada, 0 dispositivo é "[...] qualquer coisa que tenha de algum modo a capacidade de capturar, orientar, determinar, interceptar, modelar, controlar e assegurar os gestos, as condutas, as opiniões e os discursos dos seres viventes" (Agamben, 2009, p. 40). Para Zanello (2018), os dispositivos sempre se ocuparão em produzir a subjetividade e os processos de subjetivação dos sujeitos. Segundo Foucault (2006), o dispositivo exerce, portanto, um papel de dominação.

\section{Método}

A metodologia consiste em uma revisão de literatura integrativa que permite colaborações de dados diversos de estudos científicos, teóricos e empíricos agregando várias intenções (Mendes, Silveira \& Galvão, 2008). Tal metodologia sequenciou para a busca dos estudos com foco na pesquisa em periódicos nacionais na plataforma online de base de dados: Google Acadêmico, para a discussão de forma integrativa incidindo nas correlaçōes iminentes neste artigo. Foram utilizadas como literaturas de base, as obras: Microfisica do poder (2006) e a História da sexualidade 1: a vontade de saber (2015), ambas da autoria de Michel Foucault. Ao fomentar tais discussões, pretende-se igualmente, primeiro, contribuir ao propósito de conhecer e atualizar este importante debate que se faz em produções teórico-científicas dadas visivelmente por sua relevância acadêmica. Segundo, possibilitar a construção de novos apontamentos teóricos na mesma temática, refletindo sobre como as categorias de gênero e sexualidade se mostram construídas segundo discussões contemporâneas, e 0 que pode a psicologia enquanto categoria de análise científica, crítica e ética, na (e para a) quebra de paradigmas em torno desta discussão. E por último, mostrar a eficácia lógica do tão importante conceito que contribui em exame crítico aos respectivos fenômenos sociais e culturais. Considera-se enormes os esforços em torno deste tema, sobretudo em análise pelo conceito do filósofo francês.

\section{As interfaces de gênero e o dispositivo}

Na perspectiva da historiadora norte-americana Joan Scott (1995), 0 gênero é" (1) um elemento constitutivo de relações sociais baseadas nas diferenças percebidas entre os sexos e, (2) o gênero é uma forma primária de dar significado às relações de poder" (p. 86). Ou seja, as maneiras pelas quais as identidades de gênero se constituem estão ligadas a como a sociedade produziu em cada época formas de definir e padronizar as identidades masculino e feminino, isso tem em seu processo a cultura material; os objetos, e as formas decorativas de um espaço ou lugar, bem como a rotina doméstica e todo o trabalho pertinente a ela. E com isso, as relaç̃oes de poder são formadas ao passo que as diferenças entre essas identidades de gênero são constituídas por cada lugar, determinando assim os papéis do masculino e do feminino. Por exemplo, ao masculino o papel é de "forte", "dominador", "provedor", ao feminino o papel é de "frágil"e de "passividade", "delicadeza", etc. (Scott, 1995).

Neste sentido, Scott (1995), pontua que gênero é um entendimento sobre as diferenças entre o masculino e 0 feminino; que gênero vem a ser um saber que implica na diferenciação desses corpos; e ainda que, gênero; é uma categoria que possibilita verificar diferenças nas "configurações" do masculino e do feminino. Claramente, a autora propõe o uso do gênero de modo irrestrito. Os elementos que constituem o imaginário social a respeito do masculino e do feminino como aponta Scott (1995), são representados por símbolos culturalmente acessíveis, como: doutrinas religiosas, pela educação, 
pelas políticas ou questões jurídicas que acabam por contestar o binarismo de forma equivocada às noções do masculino e feminino (Torrão Filho, 2005).

Com isso, todavia, as relações de gênero são resultadas de uma construção social em que cada sociedade produz seus próprios modelos e critérios para estabelecer as relações sociais. E para que se possa compreender este fenômeno é preciso atentar-se a ele como um dispositivo do qual institui as relações das identidades de gênero como forças sobre forças (Scott, 1995). Neste sentido, Scott (1995) aponta para Foucault (2006; 2015), a a afirmar que o gênero se mostra como um dispositivo enquanto este apresenta discursos diversos, documentos, subjetividade, e um modelo determinista para a existência humana. Torrão Filho (2005), revela que Joan Scott, em sua perspectiva de gênero faz uma análise histórica e fundamenta o gênero como categoria que envolve questões para além da diferença biológica entre homens e mulheres. Ou seja, o masculino e o feminino estão amplamente estendidos a processos culturais e sociais, e de subjetivação aos quais constroem as nossas particularidades, isto é, o modo como nos identificamos a partir da nossa relação social e dentro de processos culturais; é que irão constituir nossa identidade de gênero. 0 que se aproxima da perspectiva de Foucault (2006; 2015), quanto a0 dispositivo como produtor das subjetividades e dos processos de subjetivação do sujeito social através de um processo discursivo dos amplos dispositivos sociais, como um exemplo já dado; as doutrinas religiosas.

Neste sentido, percebemos que constituir-se enquanto identidades de gênero masculino ou feminino é um processo subjetivo, sobretudo, sociocultural (Louro, 1997/2008). Além disso, os valores culturais tidos como basicamente masculinos e femininos, se tornarão constitutivos e organizarão o perfil do homem e da mulher biologicamente e socialmente, e junto a isso se estabelecem as restrições, proibições e aprovações, um modelo consequentemente repassado ao longo das gerações, influenciando também na sexualidade enquanto aspecto subjetivo do sujeito social (Oliveira, Santos \& Alves, 2013)

Em entrevista ao Cadernos Pagu com o título: Brincar de gênero, uma conversa com Berenice Bento, Berenice afirma que:" [...] ninguém tem"gênero". Fazemos gênero o tempo inteiro, somos fazedores de gênero" (Bento, 2014, p. 479). Para ela, também há a evidência da construção social dos gêneros masculino e o feminino, ela diz que" [...] devemos lutar pela abolição do gênero, esvaziá-lo do seu caráter opressor" (Bento, 2014, p. 483). Quando Berenice reflete sobre a abolição do gênero, propõe que fiquemos com a dimensão fluida; que não possui uma estrutura ou padrão, e suscita o combate às suposiç̃oes criadas por um determinismo biológico para explicar nossa subjetividade; aquilo que nos é particular e/ou de como nos orientamos respectivamente ao gênero e a sexualidade - sem que haja padrões (Bento, 2014). Corroborando com Bento (2014), de acordo com o pensamento da filósofa estadunidense Judith Butler (2016), o gênero não é estável, é socialmente construído, e por último, para ela o gênero é uma performance. Se pode executar então vários papéis, livremente, pois não há um que seja ou possa ser fixo.

Conforme Santos Filho (2013), "a nossa atual sociedade ainda lida com as condutas sexuais pela ótica do sistema de gênero inteligível, aquele para 0 qual existe uma sexualidade verdadeira, natural, divina: a heterossexualidade" (Santos Filho, 2013, p. 130). Para autor, a predominância do senso comum, 0 masculino e feminino carregam aspectos fixos desde o nascimento da pessoa, e jamais mutáveis a partir da perceptível diferença de sexo biológico: o pênis e a vagina, constituindo assim o desejo e a prática sexual para o sexo e o gênero no qual se diferencia do seu, ou seja, homem e mulher e vice-versa. Para Foucault (2015), tal como antes e ainda hoje, as questões relativas ao gênero e à sexualidade se mostram no centro do controle social, de al gum modo essas questões ganham novos contornos na sociedade de forma que se multiplicam novas instâncias discursivas e reguladoras da sexualidade humana, o que incide em novos dispositivos de controle das nossas condutas e práticas.

\section{Gênero e violência: um contraponto possível}

Outro apontamento em gênero levanta a violência como uma questão expressiva a partir do contexto de violência contra a mulher praticada pelos homens. Portanto, gênero não está distante de processos de violência, e tem seu histórico desde o passado e com força relevante na contemporaneidade (Saffioti, 2015). A autora e socióloga brasileira Heleieth Saffioti (2015), na sua obra Gênero patriarcado e violência (2015), traz uma pesquisa sobre a violência contra as mulheres entre os anos 1990 a 2000. Sendo possível para a autora colher dados de crueldades de homens contra mulheres e discuti-las teoricamente tendo em vista um processo histórico (Saffioti, 2015).

Ainda que avanços legais na instância da lei brasileira tenham sido alcançados, tendo como exemplo a Lei Maria da Penha, não se pode esquecer que a realidade de violência contra as mulheres ainda é muito expressiva. E essa boa parte tem seu agravante ligado às camadas mais pobres onde se inserem as mulheres e também trabalhadoras ${ }^{3}$ (Saffioti, 2015).

0 fenômeno da violência de gênero pelo qual Saffioti (2015) se dispõe a desvelar seu lugar e prática a partir do patriarcado - uma categoria que estabelece a dominação de homens em função das mulheres. Ou seja, as desigualdades entre homens e mulheres demandam do patriarcado, e se reverbera na sociedade atual não mais como antes, para ela o patriarcado, assim como outros fenômenos sociais, tem ganhado uma nova roupagem, afirmando que "está em permanente transformação" (Saffioti, 2015, p. 48).

Neste sentido, Foucault (2015), considera que o dispositivo também se ocupa de reinventar-se nas relações sociais, ou seja, de reproduzir e produzir novos meios de ditar e assegurar os gestos e os comportamentos humanos. Outra construção social é a de que a figura do gênero feminino deve trazer características que se vinculam ao cuidado, à família e à função da maternidade, a contrário do gênero masculino, que assume um papel social público de provedor e protetor da família (Giffin, 1994). Saffioti (2015) trabalhou em sua obra a proposta de desnaturalização dos fenômenos sociais construídos em torno da categoria de gênero, e contra a submissão de um sexo ao outro.

Concluindo as interfaces de gênero, torna-se evidente que mesmo havendo diferentes análises acerca da categoria gênero, há um campo de consenso nas discussões propostas, que é a de que o gênero é uma construção social do masculino e do feminino.

\section{A sexualidade e o dispositivo}

Cada momento da expressão da sexualidade humana é marcado por

\footnotetext{
${ }^{3}$ Em linhas gerais, neste contexto é importante frisar que Saffioti ao fazer seu recorte de gênero não trabalha afinco na questão de raça (cor), seu foco está em torno do debate da violência de gênero, discutindo e relacionando a classe social onde se ligam estes fenômenos. Recomenda-se a leitura de sua obra para uma ampla compreensão.
} 
sua história de vida, de modo que existe uma experiência sexual singular de cada pessoa que não pode ser ignorada, onde o gênero masculino ou feminino assumirá caminhos diferentes de acordo com a prática ou a experiência individual. Cada um de nós possui o direito de manifestar e elaborar de formas diferentes o modo como compreendemos a sexualidade, dado como a desenvolvemos durante o nosso percurso de vida. E as experiências, bem como a compreensão singular da sexualidade pode nos levar a manifestá-la de várias maneiras enquanto expressão ou prática. De algum modo, essa possibilidade produzirá medo, repulsa ou estranheza em algumas pessoas que possuem experiências e/ ou crenças diferentes (Soares, 2019; Moraes, Carvalhaes \& Peres, 2006; Oliveira, Santos \& Alves, 2013).

Pela mesma razão, Michel Foucault (2015) não nos deixa sem uma análise fundamentada e relevante a qual cotidianamente ouvimos (ou proferimos) a respeito da nossa ou da sexualidade de alguém, assim ele nomeia essa prática de "discursos" ou "discursos de verdade" e, ainda, como já articulamos em outro momento, o "saber", que como um dispositivo, visa igualmente regular a nossa sexualidade. Contudo, para Ribeiro (1999), Foucault não se preocupou com certa sociologia histórica que evidenciava a proibição da manifestação da sexualidade, mas sim da história política que produz a "verdade" ou as "verdades" sobre a sexualidade.

Assim, Foucault (2015), expõe que a sexualidade é" produto"nomeado; uma criação social, e, portanto, a sociedade é produtora de discursos de verdades que dão forma a nossa sexualidade, tudo isso sob as diversas formas do exercício político, seja por exemplo das administrações jurídicas ou doutrinas religiosas com o caráter de repressão ao sexo, o sexual, a sexualidade.

Neste sentido, verificamos que para Foucault (2015), os inúmeros discursos sobre a sexualidade humana, têm seu surgimento em um momento sócio histórico em instantes distintos com o objetivo de "normalizar"a sexualidade, colocando-a de acordo com a norma padrão da época; a heterossexualidade (tendo em vista a cultura ocidental), pois o controle à sexualidade só se daria então ao se controlar o corpo, o social e a política (Salles \& Ceccarelli, 2010). Desse modo, para Salles e Ceccarelli (2010) "a sexualidade é uma construção, uma invenção, inseparável do discurso e do jogo de poder dentro dos quais ela é constituída e, ao mesmo tempo, se constitui" (Salles \& Ceccarelli, 2010, p. 16).

Em conformidade com Foucault (2006; 2015), outra perspectiva aponta para o saber sobre a sexualidade ao qual "esse"saber", verdadeiro dispositivo de controle do corpo, da vida social e política, foi sendo construído e apresentado como uma revelação e/ou como uma verdade" (Ceccarelli \& Andrade, 2018, p. 234). Uma verdade que se remodela cotidianamente pela ordem religiosa, jurídica, médica e por vezes é de interesse do Estado (Ceccarelli \& Andrade, 2018). Com esses apontamentos é importante que se faça a conexão entre gênero e sexualidade, pois efetivamente são "categorias" indissociáveis, comumente apresentadas com articulações confusas, isto é, discussões sociais e acadêmicas, ainda sem uma análise ou uma fundamentação abrangente (Louro, 1997).

Certamente, é observado que as propostas acerca do termo sexualidade são amplas, e a sexualidade algo dinâmico, que pode ao longo do tempo ser mutável. A sexualidade reúne, portanto, uma série de características, tais como: afeto, carinho, carências, impulso sexual, agressividade, modo de se vestir, preferência sexual, etc., todo esse conjunto de características é dado pelas nossas experiências, características essas que nos tornam únicos, particulares, subjetivos, e que igualmente constroem a nossa identidade sexual e de gênero, são, portanto, processos infindáveis ao longo de toda a vida (Louro, 2008).
Entretanto, a sexualidade tem na contemporaneidade a análise por uma perspectiva sócio histórica, em que fica mais evidente perceber que a sexualidade, tal como se mostra no passado e no presente tem sido alvo de dispositivos; de poder e saber que normatizam, regulam e construíram verdades. Além disso, a sexualidade é um fenômeno que se mostra como uma invenção social, histórica e discursiva.

Partiu-se em particular do contexto da civilização ocidental, não se esquecendo, que há uma construção social em outros contextos sociais e históricos como, por exemplo, no oriente. Isso nos mostra que cada civilização ao longo do tempo criou a sua forma sobre como o sexual e a sexualidade devem se manifestar, soma-se a isso, a nossa realidade social inteiramente construída (Salles \& Ceccarelli, 2010; Berger \& Luckmann, 2014). Portanto, para Foucault (2015), falar sobre a história da sexualidade ao longo do desenvolvimento da sociedade, é necessário considerar, sobretudo, o enfoque conceitual de uma história dos discursos.

\section{Psicologia e dispositivos: reflexões em Michel Foucault}

Por último, e como proposta da nossa revisão de literatura veremos agora de que modo a psicologia se insere nesta discussão. Obviamente não deixamos mais claro no início este último passo, mas pretendemos aqui, colocar a psicologia como uma analítica do "Status quo" dos temas em questão, isto é, uma analítica do estado atual de como se apresenta o gênero e a sexualidade, tendo a psicologia como dispositivo analítico. Ou seja, a psicologia como uma ciência capaz de tornar claro ao sujeito conteúdos e realidades de aprisionamento, de possibilitar-Ihes certa liberdade de um ou mais dispositivos de controle. Como o dispositivo engloba proposições científicas (lembrando que é heterogêneo para Foucault), eventualmente, a psicologia se insere para contribuir igualmente para as questões de gênero e sexualidade, a passo que como uma ciência, corresponde por excelência à nossa subjetividade, pois na lógica proposta pelo dispositivo se fala de um saber, de uma verdade única desvelada sobre 0 sujeito (Cassal, Garcia \& Bicalho, 2011).

Neste sentido, Foucault permite que possamos refletir o dispositivo por um limiar relativamente positivo, de modo que para ele "é o dispositivo que permite separar não o verdadeiro do falso, mas o inqualificável cientificamente do qualificável" (Foucault, 2006, p. 247). Nessa lógica, 0 que permite que algo seja apresentado como uma hipótese "verdadeira" relevantemente aprovado, considerável e confiável, é a ciência, que em todo o seu percurso sistemático e investigativo fará o distanciamento daquilo que é inqualificável; que não apresenta confiabilidade e nem é relevante, ou que não teve aprovação científica.

É a partir desse momento no qual Foucault (2006) reflete sobre mais uma característica dos dispositivos, o seu lado positivo, pelo qual é possível apresentar a psicologia como o dispositivo que permite fazer cientificamente o distanciamento do inqualificável que persiste socialmente nos discursos e nas práticas, já destacados em outro momento deste texto.

Assim, a psicologia como ciência e profissão, se apresenta como dispositivo produtor de saber que não deve determinar, enquadrar, nem sentenciar ou julgar, mas sim libertar dos vários dispositivos que exercem 0 inqualificável, o controle, o poder ou a verdade do sexo, das identidades sexuais e das identidades de gênero (Cassal, Garcia \& Bicalho, 2011). Torna-se fun- 
damental aos profissionais da psicologia, uma atenção a "que forças estamos potencializando, que políticas de subjetivação estamos movimentando, seja nos consultórios, nos movimentos sociais, ou nos artigos, dissertações e teses que escrevemos" (Cassal Garcia \& Bicalho, 2011, p. 467). Para estes autores não há neutralidade nas práticas em psicologia, elas"produzem efeitos, que podem ser tanto de reprodução de modelos, que não nos permitem criar saídas para os processos de singularização, quanto o de trabalhar no sentido de fortalecer tais produções" (Cassal, Garcia \& Bicalho, 2011, p. 469).

A categoria de psicólogos e psicólogas (no Brasil) são constantemente convocados a responder as questões relativas à sexualidade ou mesmo ao gênero. Existem muitas formas de responder. Para Foucault (2015), a psicanálise trouxe sua marca quanto aos discursos sobre a sexualidade, ocorrendo não apenas no campo científico, mas nas falas informais do cotidiano e na variedade da produção midiática. Desse modo, os efeitos desses discursos fazem com que:

Alguns deles vão reafirmar as normas do dispositivo da sexualidade - que a relação sadia é marcada pela heterossexualidade, pela monogamia e pela finalidade reprodutiva, e a psicologia por vezes encontra respostas e justificativas naturalizantes para o dispositivo. E para aqueles que se encontram fora da norma heterossexual (heteronormatividade), especificamente, temos um complexo sistema punitivo (Cassal, Garcia \& Bicalho, 211, p. 470).

Mas como tem respondido a psicologia diante de um complexo sistema de punição às identidades de gênero e sexuais? Qual tem sido sua posição diante dos dispositivos punitivos diante das particularidades das pessoas e dos modos de ser e existir no mundo? Para responder a essas indagações as resoluções № 1, de 29 de janeiro de 2018, e a № 001 de março de 1999 do Conselho Federal de Psicologia (CFP) estabelecem normas para a atuação de psicólogas e psicólogos brasileiros, sendo que a primeira levanta uma posição clara em relação às identidades de gênero e a segunda sobre as identidades sexuais. As resoluções determinam que:

Art. $1^{0}$ - As psicólogas e os psicólogos, em sua prática profissional, atuarão segundo os princípios éticos da profissão, contribuindo com o seu conhecimento para uma reflexão voltada à eliminação da transfobia e do preconceito [...];

Art. $3^{0}$ - As psicólogas e os psicólogos, no exercício profissional, não serão coniventes e nem se omitirão perante a discriminaçãa $[\ldots]$;

Art. $4^{0}$ - As psicólogas e os psicólogos, em sua prática profissional, não se utilizarão de instrumentos ou técnicas psicológicas para criar, manter ou reforçar preconceitos, estigmas, estereótipos ou discriminações [...];

Art. 60 - As psicólogas e os psicólogos, no âmbito de sua atuação profissional, não participarão de pronunciamentos, inclusive nos meios de comunicação e internet, que legitimem ou reforcem o preconceito $[\ldots]$;

Art. 70 - As psicólogas e os psicólogos, no exercício profissional, não exercerão qualquer ação que favoreça a patologização das pessoas transexuais e travestis.

Parágrafo único: As psicólogas e os psicólogos, na sua prática profissional, reconhecerão e legitimarão a autodeterminação das pessoas transexuais e travestis em relação às suas identidades de gênero (Resolução (FP, no 1/18).

Já a resolução 01/99, determina que:

Art. $2^{\circ}$ - Os psicólogos deverão contribuir, com seu conhecimento, para uma reflexão sobre o preconceito e o desaparecimento de discriminações e estigmatizações contra aqueles que apresentam comportamentos ou práticas homoeróticas.

Art. $3^{\circ}$ - os psicólogos não exercerão qualquer ação que favoreça a patologização de comportamentos ou práticas homoeróticas, nem adotarão ação coercitiva tendente a orientar homossexuais para tratamentos não solicitados.

Parágrafo único - Os psicólogos não colaborarão com eventos e serviços que proponham tratamento e cura das homossexualidades.

Art. $4^{\circ}$ - Os psicólogos não se pronunciarão, nem participarão de pronunciamentos públicos, nos meios de comunicação de massa, de modo a reforçar os preconceitos sociais existentes em relação aos homossexuais como portadores de qualquer desordem psíquica (Resolução (FP, nº 01/99).

A partir dessas considerações, os estudos foucaultianos apontam para a necessidade de um desacomodar da ciência psicológica. Significa dizer que, por vezes como o dispositivo tem a estratégia dominante; a psicologia pode produzir discursos dominantes, e, portanto, essa ciência, deve sempre estar atenta aos seus discursos científicos e a sua ética em direção ao sujeito-objeto do seu estudo, para não produzir ou reproduzir práticas que alienam, normalizam, institucionalizam, determinam e ordenam os processos de subjetivação e o sujeito subjetivo (Hüning \& Guareschi, 2014; Cavalcante, Silva, Gomes \& Huning, 2016).

Eis aí então, a Psicologia como o dispositivo que carrega a responsabilidade de não pactuar com o aprisionamento dos seres humanos, mas de desvencilha-los, desprendê-los de elementos constitutivos que produzem o sofrimento. Enfim, trata-se de viabilizar e construir uma psicologia cada vez mais comprometida com a liberdade do sujeito e com a produção de qualidade de vida. 


\section{Resultados e discussões}

Utilizamos duas leituras de base, especificamente de Michel Foucault, destacadas na introdução. As duas obras são aportes que, circunscrevem a fundamentação teórico-metodológico desta revisão, para a análise das categorias em questão e das produções teóricas analisadas.

Foram utilizados 15 (quinze) artigos que coadunam com a perspectiva do conceito de dispositivo encontrados na base de dados: Google Acadêmico, sendo que deste número, 5 (cinco) também podem ser encontrados na base de dados SciELO - Scientific Electronic Library Online, com foco em periódicos nacionais, abordando especificamente a temática do conceito de dispositivo de Michel Foucault, o gênero, a sexualidade e a psicologia. Os 15 artigos foram selecionados para a leitura utilizando as palavras-chaves: gênero, sexualidade, foucault, psicologia. (Ex: na barra de pesquisa: "a sexualidade para foucault"; "foucault e a psicologia"; "dispositivo e sexualidade"). A adoção dos quinze estudos permitiu enriquecer nossa revisão integrativa de literatura, sendo possivivel associar a perspectiva teórica dos encontrados as literaturas de base, possibilitando atualizações ao "debate" proposto.

Dentre os 15 estudos, 5 (cinco) artigos abordam a temática de gênero relacionado ao conceito de dispositivo, outros 9 (nove) abordam a temática da sexualidade em consonância com o conceito de dispositivo, dentre estes: dois fazem contribuiç̃oes teóricas relacionando a psicologia em análise do dispositivo.

Contou-se com duas resoluçôes do Conselho Federal de Psicologia - CFP, a 01/2018 que abordam a temática de gênero, ea 01/1999 sobre sexualidade. Outros estudos, fortaleceram os achados dispostos na tabela e abordam de modo geral: psicologia, gênero, sexualidade, dispositivo, construção social e subjetividade. Apenas três artigos nas áreas de: Enfermagem, Direito e Dança, discutiam o conceito em questão de forma empírica/prática, analisando e articulando as teorias da sexualidade. São os autores: Ribeiro, (1999), Soares (2019), Oliveira, Santos e Alves (2013), Paixão (2013). Estes autores debatiam pela mesma lógica, como a sexualidade ao longo dos anos esteve atrelada ao sistema da realidade construída numa perspectiva sócio histórica. Outro aspecto encontrado, diz respeito ao modo como essa construção se estende às práticas nas respectivas áreas, e a posição do gênero alocado a papéis socialmente construídos para o homem ou a mulher. Tal como a dança, que ao longo do tempo, estabeleceu-se como um lugar apenas do feminino.

Por fim, foram encontradas duas literaturas com reflexões que aproximavam à psicologia no âmbito de gênero e sexualidade em cunho Nacional. São elas dos autores: Cavalcante et al (2016) e Cassal, Garcia e Bicalho (2011). Eles abordaram de forma teórica e científica, como a psicologia enquanto ciência que se ocupa da subjetividade humana deve continuamente estar atenta aos seus documentos éticos e científicos, ao passo que pelo conceito de dispositivo, deve estar instrumentalizada como um campo de possibilidades, voltada para desnaturalizar práticas e discursos presentes em sistemas inteligíveis direcionadas às especificidades da sexualidade e do gênero.

Scott (1995), Bento (2014), Moraes, Carvalhaes e Peres (2006), Giffin (1994) eTorrão Filho (2005), discutem gênero pela perspectiva sócio histórica e colaboram para uma reflexão em Foucault (2015), ao desenvolverem apontamentos que revelam que os papéis de gênero são socialmente construídos em que os símbolos culturais da nossa realidade material, igualmente produziram discursos em direção aos sujeitos masculino e feminino; Ihes atribuindo papéis distintos, que não devem se manifestar de maneira diferente do que Ihes foi determinado.
Em consonância com os apontamentos teóricos, os autores Ceccarelli e Andrade (2018), Ferreirinha e Raitz (2010), Salles e Ceccarelli (2010), Soares (2019), e Santos Filho (2013), explanam que a sexualidade também se dá pela real materialidade das construçōes sociais, expondo que a contemporaneidade em larga escala, reproduz condutas paradigmáticas, mesmo no âmbito das diversas práticas profissionais, conforme destacado por Soares (2019), ainda se reproduz por vezes tais comportamentos e falas naturalistas, binárias e excludentes. E finalmente, bem como retrata Foucault (2015), onde para ele os discursos naturalistas (portado como um dispositivo) visam normatizar o sexo e a sexualidade, performances de gênero, e possivelmente toda a conduta humana.

\section{Considerações finais}

Entende-se que tanto o gênero como a sexualidade, enquanto dispositivos, se pronunciaram ao longo da história através de discursos deterministas sobre o sujeito, corpo, práticas e manifestações de sexualidade. Com a finalização das leituras, foi possível perceber que os temas: gênero e sexualidade aparecem com significados distintos ao longo da história, segundo as diferentes vertentes de pensamento. Reiteramos o importante papel da Psicologia, enquanto um dos dispositivos da ciência, que tem se encarregado de exercer uma função reconhecida no que tange, ao enfrentamento das opressões e violências produzidas pelos atravessamentos em torno das questões de gênero e sexualidade no Brasil.

Neste sentido, salientamos que o conceito de dispositivo é um importante instrumento teórico-metodológico para fundamentar as discussões em torno das categorias de gênero, sexualidade, e a análise das proposições da psicologia no tocante aos elementos discutidos. 0 objetivo deste trabalho foi de apresentar, relacionar, e discutir o conceito de dispositivo de Michel Foucault (1926-1984), articulando às categorias: gênero, sexualidade, e a psicologia, como elementos norteadores que não perdem de vista ou/e não estão distantes das proposições do conceito em questão.

Tal proposta, ao trazer discussões em torno do conceito de dispositivo, pode contribuir para pensarmos criticamente a realidade cotidiana, muito imbricada por diferenciações que produzem desvantagens no modo como as pessoas são a locadas no tecido social. Éimportante frisar e nos atentarmos ao fato de que algumas produções acadêmicas, por não discutirem os conceitos a partir de um único prisma de significado, podem contribuir para o não atendimento das questões oriundas desta organização social das diferenças.

Salientamos que a universidade tem um papel importante no processo de comunicação com a comunidade, ultrapassando os limites de seus muros e acervos. Ela deve de maneira efetiva, possibilitar a desconstrução de preconceitos e quebrar paradigmas limitantes através da oferta de espaços que debatam o gênero e a sexualidade nos campos de ensino, pesquisa e extensão. Esta pesquisa pode servir como substrato, ainda que tímido, para propiciar consciência da realidade social, cultural e econômica na qual as desigualdades são produzidas. Portanto, seria importante que as pesquisadoras e pesquisadores, sujeitos de certo saber/poder, conseguissem pensar num processo de aproximação mais amistoso entre 0 saber científico e o popular, pois ainda estamos muito distantes de uma realidade em que os debates que giram em torno das violações do gênero e da sexualidade não sejam mais necessários. Por fim, ressaltamos que todos os achados acerca do conceito de dispositivo aqui mencionados, são de suma importância para reforçar a importância do 
legado de" descontentamento"deixado pelo filósofo francês Michel Foucault, que tanto contribuiu e se faz tão atual no que tange aos questionamentos sobre a necessidade de pensar e agir sobre os processos de desnaturalização/ desconstrução de costumes, crenças e papéis que tanto oprimem e potencializam a permanência de desconfortos na vida contemporânea.

Tabela 1. Artigos utilizados para fundamentação teórica do presente artigo.

\begin{tabular}{|c|c|c|c|}
\hline Estudo & Foco do estudo & Concepção de dispositivo & Conclusão \\
\hline BENTO, B. (2014) & Gênero & $\begin{array}{l}\text { Enfoque ao dispositivo de } \\
\text { gênero. }\end{array}$ & $\begin{array}{l}\text { Entrevista sobre a concepção de gênero como } \\
\text { uma construção social }\end{array}$ \\
\hline $\begin{array}{l}\text { CAVALCANTE, L. } \\
\text { et al (2016) }\end{array}$ & Psicologia & $\begin{array}{l}\text { Enfoque à psicologia } \\
\text { enquanto dispositivo }\end{array}$ & $\begin{array}{l}\text { Michel Foucault e a história da psicologia e seu } \\
\text { desenvolvimento no Brasil }\end{array}$ \\
\hline $\begin{array}{l}\text { CASSAL, L.C.B; } \\
\text { GARCIA, A.M; } \\
\text { BICALHO, P.P.P.G. } \\
\text { (2011) }\end{array}$ & $\begin{array}{l}\text { Psicologia, } \\
\text { Dispositivo, } \\
\text { Sexualidade }\end{array}$ & $\begin{array}{l}\text { Utiliza para analisar a } \\
\text { identidade sexual }\end{array}$ & $\begin{array}{l}\text { Identidade sexual na Biopolítica e processos de } \\
\text { criminalização na ótica do conceito de } \\
\text { dispositivo }\end{array}$ \\
\hline $\begin{array}{l}\text { CECCARELLI, } \mathrm{P} \text {; } \\
\text { ANDRADE, E. } \\
(2018)\end{array}$ & $\begin{array}{l}\text { Sexual, } \\
\text { Sexualidade, } \\
\text { Contemporâneo }\end{array}$ & $\begin{array}{l}\text { Utiliza para analisar a } \\
\text { sexualidade }\end{array}$ & $\begin{array}{l}\text { O sexual e a sexualidade em vista do conceito } \\
\text { de dispositivo }\end{array}$ \\
\hline $\begin{array}{l}\text { FERREIRINHA, I; } \\
\text { RAITZ, T. (2010) }\end{array}$ & Poder & $\begin{array}{l}\text { Utiliza para analisar a } \\
\text { concepção de poder } \\
\text { enquanto dispositivo }\end{array}$ & $\begin{array}{l}\text { Reflexão teórica sobre as relações de poder em } \\
\text { Michel Foucault }\end{array}$ \\
\hline GIFFIN, K. (1994) & $\begin{array}{l}\text { Violência, Gênero, } \\
\text { Sexualidade, Saúde }\end{array}$ & $\begin{array}{l}\text { Enfoque em saúde } \\
\text { enquanto dispositivo }\end{array}$ & $\begin{array}{l}\text { Diferenças na violência de gênero na } \\
\text { perspectiva da sexualidade, sobretudo no } \\
\text { campo da saúde }\end{array}$ \\
\hline $\begin{array}{l}\text { MORAES, P; } \\
\text { CARVALHAES, } \\
\text { R.S; PERES, W.S. } \\
(2006)\end{array}$ & $\begin{array}{l}\text { Sexualidade, } \\
\text { Gênero, Dispositivo }\end{array}$ & $\begin{array}{l}\text { Utiliza para analisar } \\
\text { gênero e sexualidade }\end{array}$ & $\begin{array}{l}\text { Estudo sobre as categorias: gênero e } \\
\text { sexualidade na perspectiva do conceito de } \\
\text { dispositivo }\end{array}$ \\
\hline $\begin{array}{l}\text { OLIVEIRA, A; } \\
\text { SANTOS, C.O; } \\
\text { ALVES, M.P. (2013) }\end{array}$ & $\begin{array}{l}\text { Dança, Corpo, } \\
\text { Sexualidade }\end{array}$ & $\begin{array}{l}\text { Enfoque em danças } \\
\text { enquanto dispositivos }\end{array}$ & $\begin{array}{l}\text { A dança, o corpo e a sexualidade como } \\
\text { advindos de um processo de naturalização } \\
\text { entre o que é do masculino e do feminino }\end{array}$ \\
\hline PAIXÄO, H. (2013) & Moda, Saber, Poder & $\begin{array}{l}\text { Utiliza para analisar a } \\
\text { estética, o saber e o poder }\end{array}$ & $\begin{array}{l}\text { Dissertação de mestrado: analisar pelo } \\
\text { conceito de dispositivo quais poderes e saberes } \\
\text { ditam os padrões da moda }\end{array}$ \\
\hline RIBEIRO, M. (1999) & $\begin{array}{l}\text { Sexualidade, } \\
\text { Enfermagem }\end{array}$ & $\begin{array}{l}\text { Utiliza para analisar a } \\
\text { sexualidade no âmbito da } \\
\text { saúde }\end{array}$ & $\begin{array}{l}\text { A sexualidade em Michel Foucault como } \\
\text { contribuição para a área da enfermagem no } \\
\text { Brasil }\end{array}$ \\
\hline SCOTT, J. (1995) & Gênero & $\begin{array}{l}\text { Enfoque em gênero } \\
\text { enquanto processo } \\
\text { histórico entre dispositivos }\end{array}$ & $\begin{array}{l}\text { Gênero visto de um ponto de vista histórico, } \\
\text { constituído e mutável }\end{array}$ \\
\hline $\begin{array}{l}\text { SALLES, A; } \\
\text { CECCARELII, P. } \\
(2010)\end{array}$ & Sexualidade & $\begin{array}{l}\text { Utiliza para analisar a } \\
\text { sexualidade }\end{array}$ & $\begin{array}{l}\text { Discutir e relacionar a sexualidade na } \\
\text { perspectiva de Michel Foucault }\end{array}$ \\
\hline SOARES, D. (2019) & $\begin{array}{l}\text { Homossexualidade, } \\
\text { Direitos Humanos }\end{array}$ & Sem enfoque & $\begin{array}{l}\text { Análise de estudos da homossexualidade e os } \\
\text { direitos humanos para essa orientação no Brasil }\end{array}$ \\
\hline $\begin{array}{l}\text { SANTOS FILHO, I. } \\
(2013)\end{array}$ & Sexualidade & Sem enfoque & $\begin{array}{l}\text { A sexualidade como construção } \\
\text { mutável/volúvel }\end{array}$ \\
\hline $\begin{array}{l}\text { TORRÄO FILHO, A. } \\
(2005)\end{array}$ & Gênero & $\begin{array}{l}\text { Utiliza para analisar a } \\
\text { concepção de gênero }\end{array}$ & $\begin{array}{l}\text { Gênero na perspectiva do conceito de } \\
\text { dispositivo e como construção social }\end{array}$ \\
\hline
\end{tabular}




\section{Referências}

Agamben, G. (2009). O que é o contemporâneo? e outros ensaios. Chapecó: Argos.

Berger, P.L \& Luckmann, T. (2014). A construção social da realidade: tratado de sociologia do conhecimento (36. ed.), Petrópolis: Vozes.

Butler, J. (2016). Problemas de gênero: feminismo e subversão da identidade (11. ed.), Rio de Janeiro: Civilização Brasileira.

Brasil. (2019). Resolução (FP no 1/2018. Estabelece normas de atuação para as psicólogas e os psicólogos em relação às pessoas transexuais e travestis. Brasília: Conselho Federal de Psicologia.

Brasil. (2019). Resolução (FP no 001/1999. Estabelece normas de atuação para os psicólogos em relação à questão da Orientação Sexual. Brasília: Conselho Federal de Psicologia.

Bento, B. (2014). Brincar de gênero, uma conversa com Berenice Bento. Diego Madi Dias. Cadernos Pagu, Campinas, (43), 475-497.

Cavalcante, L.M, Silva, A.K, Gomes, C.A.R \& Huning, S. (2016). Foucault e a Psicologia no Brasil: interlocuções e novas perspectivas. Revista Polis e Psique, 6(2), 146-165.

Cassal, L.C.B., Garcia, A.M \& Bicalho, P.P.P.G. (2011). Psicologia e o dispositivo da sexualidade: biopolítica, identidades e processos de criminalização. Psico, 42(4), 465-473.

Ceccarelli, P.R \& Andrade, E.L. (2018). 0 sexual, a sexualidade e suas apresentações na atualidade. Revista Latinoamericana de Psicopatologia Fundamental, 21(2), 229-250.

Ferreirinha, I.M.N \& Raitz, T. R. (2010). As relações de poder em Michel Foucault: reflexões teóricas. Revista de Administração Pública - RAP, Rio de Janeiro, 44(2), 367-383.

Foucault, M. (2015). História da sexualidade 1: A vontade de saber. 3. ed. São Paulo: Paz e Terra.

Foucault, M. (2006). Microfísica do poder. 22. ed. Rio de Janeiro: Edições Graal.

Giffi, K. (1994). Violência de gênero, sexualidade e saúde. Caderno de Saúde Pública, 10(1), 146-155.

Hüning, S.M \& Guareschi, N.M.F. (2014). Efeito Foucault: desacomodar a psicologia. In: S.M. Hüning \& N.M.F. Guareschi, (Orgs). et al. Foucault e a Psicologia (pp. 159-182). Porto Alegre: EDIPUCRS.

Louro, G.L. (1997). Gênero, sexualidade e educação: uma perspectiva pós-estruturalista. Petrópolis-RJ: Vozes.

Louro, G.L. (2000). Pedagogias da sexualidade. In: G.L. Louro(Org), O corpo educado:pedagogias da sexualidade (pp. 07-26) Belo Horizonte: Autêntica.

Louro, G.L. (2008). Gênero e sexualidade: pedagogias contemporâneas. Revista Pro-Posições, Campinas-SP, 19(2), 17-23.

Mendes, K.D.S, Silveira, R.C.C.P \& Galvão, C.P. (2008). Revisão integrativa: método de pesquisa para a incorporação de evidências na saúde e na enfermagem. Revista Texto Contexto Enfermagem, 17(4), 758-764.

Moraes, P.P., Carvalhaes, R.S \& Peres, W.S. (2006). Do dispositivo das sexualidades ao dispositivo de gênero: um percurso de estudo. Recuperado de http:// wwW2.assis.unesp.br/encontrosdepsicologia/ANAIS_DO_XIX_ENCONTRO/114_PALOMA_PRISCILA_DE_MORAES.pdf. em: 03 de jun. 2019.

Oliveira, A.M., Santos, C.O \& Alves, M.P. (2013). Corpo e sexualidade: os processos de normalização na dança. Revista Cadernos UniFOA, Volta Redonda-RJ, 8(1), 23-37.

Paixão, H.P. (2013). Saber, poder e sujeito no dispositivo da moda. Dissertação (Mestrado em Linguística), Programa de Pós-graduação em Estudos Linguísticos, Universidade Federal de Goiás.

Ribeiro, M.0. (1999). A sexualidade segundo Michel Foucault: uma contribuição para a enfermagem. Revista da Escola de Enfermagem da USP, 33(4), 358-363.

Souza, M.T, Silva, M.D \& Carvalho, R. (2010). Revisão integrativa: o que é e como fazer. Einstein, 8(1), 102-106.
Scott, J. (1995). Gênero: uma categoria útil de análise histórica. Revista Educação \& Realidade, Porto Alegre, 20(2), 71-99.

Salles, A.C.T.C \& Ceccarelli, P.R. (2010). A invenção da sexualidade. Reverso, Belo Horizonte, 32(60), 15-24.

Soares, D.V. (2019). 0 estudo da orientação homossexual pensado nos direitos humanos e na sociedade brasileira. Revista Bagoas, Rio Grande do Norte, 13(20), 121-163.

Santos Filho, I.I. (2013). Em tempos de sexualidade plástica, 0 item lexical "heteroafinidade". Revista Bagoas, Rio Grande do Norte, 6(8), 126-146.

Saffioti, H. (2015). Gênero patriarcado e violência. (2. ed). São Paulo: Expressão Popular: Fundação Perseu Abramo.

Santos, I.C., Lemos, F.C.S., Cardoso, W.R.S \& Brito Neto, J.A. (2018). História, psicologia e política em Michel Foucault. In: 0.L. Mattioli \& M.F. Araúio, (Orgs). Violência e relações de gênero: dez anos de publicações e pesquisas. (pp. 49-62) Curitiba: CRV.

Torrão Filho, A. (2005). Uma questão de gênero: onde o masculino e o feminino se cruzam. Cadernos Pagu, Campinas-SP, (24), 127-152.

Weinmann, A.0. (2006). Dispositivo: um solo para a subjetivação. Psicologia \& Sociedade, São Paulo, 18(3), 16-22.

Zanello, V. (2018). Saúde mental, gênero e dispositivos: cultura e processos de subjetivação. Curitiba: Appris. 